\title{
Bilateral Consequences of Chronic Unilateral Deafferentation in the Auditory System of the Cricket Gryllus bimaculatus
}

\author{
Hadley Wilson Horch ${ }^{a} \quad$ Elizabeth Sheldon ${ }^{b} \quad$ Claire C. Cutting ${ }^{c} \quad$ Claire R. Williams $^{d}$ \\ Dana M. Riker ${ }^{\mathrm{e}}$ Hannah R. Peckler ${ }^{\mathrm{a}}$ Rohit B. Sangal ${ }^{\mathrm{a}}$ \\ ${ }^{a}$ Department of Biology, Bowdoin College, Brunswick, Me., ${ }^{b}$ Albany Medical College, Albany, N.Y., \\ 'Division of Genetics, Department of Medicine, Brigham and Women's Hospital, dChildren's Hospital Boston, \\ Harvard Medical School, Boston, Mass., and 'Franciscan Hospital for Children, Brighton, Mass., USA
}

\section{Key Words}

Auditory system - Axonal development - Dendrites •

Neuronal plasticity $\cdot$ Regeneration $\cdot$ Axon guidance $\cdot$

Chemoattractant $\cdot$ Invertebrate

\begin{abstract}
The auditory system of the cricket has the unusual ability to respond to deafferentation by compensatory growth and synapse formation. Auditory interneurons such as ascending neuron 2 (AN-2) in the cricket Gryllus bimaculatus possess a dendritic arbor that normally grows up to, but not over, the midline of the prothoracic ganglion. After chronic deafferentation throughout larval development, however, the AN-2 dendritic arbor changes dramatically, and medial dendrites sprout across the midline where they form compensatory synapses with the auditory afferents from the contralateral ear. We quantified the extent of the effects of chronic, unilateral deafferentation by measuring several cellular parameters of 3 different neuronal components of the auditory system: the deafferented AN-2, the contralateral (or nondeafferented) AN-2 and the contralateral auditory afferents. Neuronal tracers and confocal microscopy were used to visualize neurons, and double-label experiments were performed to examine the cellular relationship between pairs of
\end{abstract}

cells. Dendritic complexity was quantified using a modified Sholl analysis, and the length and volume of processes and presynaptic varicosities were assessed under control and deafferented conditions. Chronic deafferentation significantly influenced the morphology of all 3 neuronal components examined. The overall dendritic complexity of the deafferented AN-2 dendritic arbor was reduced, while both the contralateral $\mathrm{AN}-2$ dendritic arbor and the remaining, intact, auditory afferents grew longer. We found no significant changes in the volume or density of varicosities after deafferentation. These complex cellular changes after deafferentation are interpreted in the light of the reported differential regulation of vesicle-associated membrane protein and semaphorin $2 a$.

Copyright $\odot 2011$ S. Karger AG, Basel

\section{Introduction}

An elaborate system of intrinsic and extrinsic factors is thought to control the development of the nervous system. Exciting advances over the last two decades have improved our understanding of the factors that influence axonal development and synapse formation [TessierLavigne et al., 1988; Cheng et al., 1995; Tessier-Lavigne

\section{KARGER}

(๑) 2011 S. Karger AG, Basel

Fax +4161306 1234

E-Mail karger@karger.ch

www.karger.com
Accessible online at: www.karger.com/dne
Hadley Wilson Horch

Department of Biology

Bowdoin College

Brunswick, ME 04011 (USA)

Tel. +1 207798 4128, E-Mail hhorch@bowdoin.edu 


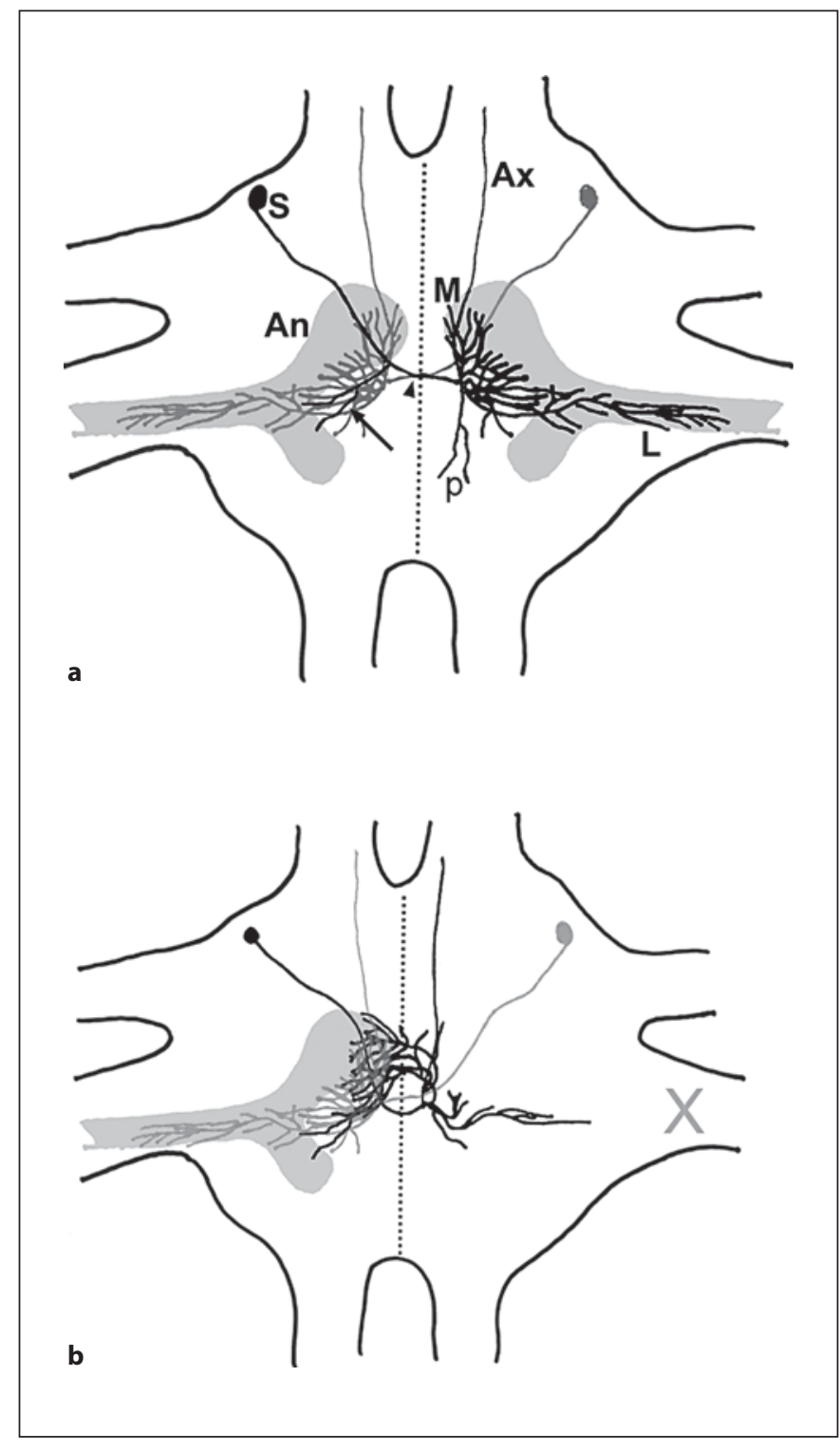

Fig. 1. Schematic of the relevant parts of the adult cricket auditory system and the effects of chronic deafferentation on AN-2 dendrites. a The prothoracic ganglion (outline) contains a number of auditory interneurons which exist in mirror image pairs. A mirror image AN-2 pair is shown (black and gray), and the relevant parts of the right AN-2 (black), as defined by the side of the dendritic arbor, are labeled: $\mathrm{S}=$ Soma; $\mathrm{Ax}=$ axon; $\mathrm{M}=$ medial dendrites; $\mathrm{L}=$ lateral dendrites; $\mathrm{p}=$ posterior dendrites. Arrow: contralateral tuft, which does not appear to receive significant excitatory input from the contralateral ear. Arrowhead: primary neurite which crosses the midline and connects the soma to the dendritic arbor. The auditory afferents are shown bilaterally in light gray, and they end in the claw-shaped auditory neuropil. b Chronic deafferentation on the right $(\mathrm{X})$ results in the unilateral degeneration of the auditory nerve and induces profound reorganization of the ipsilateral AN-2 dendrites (black AN-2). The contralateral (or nondeafferented) AN-2 (light gray) and the contralateral auditory nerve (gray) remain intact. and Goodman, 1996; Kidd et al., 1999; Dalva et al., 2000; Wen and Zheng, 2006; Polleux et al., 2007]. Recent work has further indicated that many of the factors that influence developing axons also influence the growth and maturation of dendrites during development [McAllister, 2002; Furrer et al., 2003; Komiyama et al., 2007], though often in different or unpredictable ways [Polleux et al., 2000; Poon et al., 2008]. Deafferentation, or a loss of presynaptic input during vertebrate or invertebrate development, can result in profound dendritic retraction [Murphey et al., 1975; Benes et al., 1977; Deitch and Rubel, 1984; Mizrahi and Libersat, 2002] or even cell death [Parks, 1979; Born and Rubel, 1985; Sherrard and Bower, 1998; Baldi et al., 2000].

The auditory system of the cricket provides a remarkable system in which to examine postembryonic dendritic plasticity since deafferentation has been shown to induce robust dendritic sprouting both during larval development and in the adult [Hoy et al., 1985; Schildberger et al., 1986; Brodfuehrer and Hoy, 1988]. Auditory signals, transduced by the auditory organ located in the tibia of each foreleg, are carried by auditory afferents into the prothoracic ganglia of the central nervous system (CNS) where they end in a 'claw-like' shape (gray, fig. 1). The auditory neurons form synapses with a number of postsynaptic auditory interneurons, which exist in mirror image pairs. One such pair of cells (black and gray, fig. 1a) is known as ascending neuron $2(\mathrm{AN}-2)$ in the cricket Gryllus bimaculatus. Because the majority of AN-2 dendrites grow up to, but not over, the midline of the CNS, each AN-2 is considered to be ipsilateral to its source of auditory input.

As has been demonstrated in two different cricket species, chronic deafferentation of the auditory neurons, via amputation of the foreleg, throughout the majority of larval development causes a profound alteration in the morphology of deafferented dendrites [Hoy et al., 1985; Schildberger et al., 1986]. Both types of ascending neurons as well as both omega neurons [Schildberger et al., 1986] respond to this deafferentation by sending dendritic sprouts across the boundary of the midline, as illustrated here for AN-2 (fig. 1b). These dendrites form compensatory synaptic connections with the auditory afferents from the contralateral ear, which restore normal threshold and intensity characteristics [Hoy et al., 1985; Schildberger et al., 1986]. Experiments in the adult indicate that the physiological characteristics of the contralateral AN-2 on the intact side (or nondeafferented; light gray, fig. 1b) remain unchanged after deafferentation in the adult [Brodfuehrer and Hoy, 1988]. This work implies that the 
remaining, intact auditory input must somehow accommodate new synaptic demand without compromising the functionality of its original synaptic connections.

The goal of the work presented here was to quantify the changes in adult morphology of three specific components of the auditory system after chronic deafferentation: (1) the deafferented AN-2 dendrites (black, fig. 1b), (2) the contralateral (nondeafferented) $\mathrm{AN}-2$ dendrites from the intact side (light gray, fig. 1b), and (3) the auditory afferents on the intact side (gray claw, fig. 1b). Our anatomical analyses inform our ongoing search and study of molecular candidates that may influence the morphological plasticity of dendrites and axons after unilateral deafferentation. For example, we present preliminary evidence that the transcript levels of two molecular candidates, vesicle-associated membrane protein (vamp) and semaphorin $2 \mathrm{a}$ (sema $2 a$ ), undergo quantifiable changes in expression levels upon deafferentation. Thus, with these results we can paint the most complete and detailed picture to date of the broad cellular and molecular changes induced by deafferentation in the cricket auditory system.

\section{Materials and Methods}

\section{Animals and Deafferentation}

A colony of Mediterranean field crickets, G. bimaculatus (originally supplied by Ron Hoy, Cornell University), was maintained as previously described [Horch et al., 2009]. Crickets were chronically deafferented by amputating the right foreleg above the tibial-femoral joint beginning in the first larval instar. Regenerative blastemas were removed as needed. For molecular studies, young adult crickets were used (1 week or younger), and upon reaching adulthood, they underwent a single, unilateral amputation. Approximately 150 crickets, both male and female, were used for these experiments.

\section{Neuronal Backfills}

Backfills were performed as previously described [Horch et al., 2009], except on adult crickets only. AN-2 was always backfilled with $4 \%$ unconjugated biocytin (in $50 \mathrm{~mm}$ sodium bicarbonate buffer). Auditory afferents were usually backfilled with $1 \mathrm{mg} / \mu \mathrm{l}$ Alexa Fluor 594-conjugated biocytin in cricket saline $(140 \mathrm{~mm}$ $\mathrm{NaCl}, 5 \mathrm{mM} \mathrm{KCl}, 7 \mathrm{mM} \mathrm{CaCl} 2-2 \mathrm{H}_{2} \mathrm{O}, 1 \mathrm{mM} \mathrm{MgCl}_{2}-6 \mathrm{H}_{2} \mathrm{O}, 5 \mathrm{mM}$ TES, $4 \mathrm{mM} \mathrm{NaHCO}_{3}, 5 \mathrm{~mm}$ trehalose, $\mathrm{pH}$ 7.3). For the auditory neuron preparations used for the analysis of varicosities, $4 \%$ unconjugated biocytin was used.

\section{Immunohistochemistry}

All fixed ganglia with biocytin fills (double or single fills) were rinsed in PBS and then treated $4 \times 1 \mathrm{~h}$ in $0.5 \%$ Triton X-100 in rinse solution ( $0.05 \mathrm{M} \mathrm{NaHCO}_{3}, 0.15 \mathrm{M} \mathrm{NaCl}, \mathrm{pH}$ 8). Biocytin was visualized using 1:400 streptavidin Alexa Fluor 488 (Invitrogen, Carlsbad, Calif., USA) in $0.5 \%$ Triton X-100 rinse solution for $36-44 \mathrm{~h}$ at $4^{\circ} \mathrm{C}$. Ganglia were then rinsed in the rinse solution $(4 \times 1 \mathrm{~h})$, dehydrated and mounted in methyl salicylate with coverslip spacers.

\section{Confocal Microscopy and Midline Determination}

Images were collected with a laser scanning confocal microscope LSM 510 META (Zeiss, Thornwood, N.Y., USA) using the Plan-Neofluar $\times 40 / 1.3$ objective or the Plan-Apochromat $\times 100 / 1.4$ objective. The location of the midline was determined both by examining the midpoint between the intraganglionic connectives in low-power images, and by matching this with $\times 40$ images at high gain, revealing the autofluorescent cells at the midline.

\section{Sholl Analysis}

Analysis was only performed on images in which AN-2 alone was filled. A modified Sholl analysis of AN-2 dendritic complexity was performed by laying acetate sheets printed with concentric rings directly on the computer monitor, displaying the three-dimensional image of each neuron. Each point at which a dendrite intersected with a ring was marked while the three-dimensional volume of the cell was stepped through using Volocity (Improvision, Waltham, Mass., USA). Five cells per condition were analyzed. The contribution of the contralateral tuft was noted so it could be analyzed separately. The sparse posterior branches of AN-2 (labeled ' $p$ ' in fig. 1a) were excluded from this analysis. A 2 $\times 2$ repeated measures ANOVA was performed first with 'side' as a within-group factor and 'treatment' as a between-group factor. Then, separate ANOVA were performed on each side with 'distance from the midline' as a within-group factor and 'treatment' as a between-group factor. The dendritic intersections were grouped as either medial (rings 1-33) or lateral dendrites (34th to last ring), and the average values were analyzed. The coefficient of variation was calculated by dividing the standard deviation by the mean for each ring.

\section{Quantification of Dendritic and Axonal Arbor Parameters}

The overall extent of the dendritic arbor was determined by measuring the distance from the midline to the tip of the longest dendrite in image montages made up of two or three individual images. An ANOVA was performed to determine statistical differences in length. The maximal extent of axonal growth across the midline was measured similarly. The number of dendrites and axons crossing the midline were counted, and Volocity was used to measure the volume of all auditory axons that crossed the midline. All these measurements were made blind to condition. Statistical analyses of all axonal measurements were analyzed using a t test.

\section{Analysis of Varicosities}

Three-dimensional confocal images collected with the $\times 100$ objective were used to identify varicosity-like objects based on percent gray value using Volocity. Objects were limited to those within the appropriate range according to the ultrastructural measurements by Hardt and Watson [1999]. The varicosity density was calculated by measuring the total process volume and calculating the number of varicosities divided by the total volume of processes. All statistical analyses were performed using a t test.

\section{Tissue Extraction and RNA Isolation}

Total RNA from individual prothoracic ganglia was isolated using the QIAGEN RNeasy Mini Kit (Qiagen, Valencia, Calif., USA). DNase (QIAGEN) treatment 'on column' was performed to remove residual DNA before elution in water. RNA purity and 
concentration were assessed using a NanoDrop 1000 Spectrophotometer (Thermoscientific, Wilmington, Del., USA) and stored at $-80^{\circ} \mathrm{C}$.

\section{cDNA Synthesis}

cDNA was synthesized in a reverse transcriptase reaction from 100 ng total RNA using the SuperScript III First-Strand Synthesis System (Invitrogen, Carlsbad, Calif., USA) following the protocol outlined in Nolan et al. [2006]. cDNA reactions were primed with one of two gene-specific primers: $5^{\prime}$-CGTACCACTGCACCACTTTG-3' for sema2a (accession No. EF036538) and 5'-GCAATCTCGGCAATATCCTT-3' for VAMP (accession No. GT564740). $25 \mu \mathrm{l}$ of samples were incubated at $65^{\circ} \mathrm{C}$ for 30 min. Samples were run with and without reverse transcriptase to control for genomic DNA contamination.

\section{Reverse Transcriptase-Quantitative PCR}

Reverse transcriptase-quantitative PCR (RT-qPCR) was performed following the protocol in Nolan et al. [2006] using a StepOne Real-Time PCR System (Applied Biosystems, Foster City, Calif., USA). Forward and reverse primers used to amplify sema2a were 5'-CACGGTGCTGAACTTCATTC-3' and 5'-CGTTATTTGTTCCGGCGTAG-3', respectively. Those for vamp were $5^{\prime}$-ACGCCACAATGTCATTTGAA- ${ }^{\prime}$ and $5^{\prime}$-ACAACCTCTTCCACCTGTGC-3', respectively. Templates were added to $2 \times$ stock Power SYBR Green PCR Master Mix (Applied Biosystems) and run in triplicate. The cycling parameters for sema $2 a$ amplification were $95^{\circ} \mathrm{C}$ for $15 \mathrm{~s}, 62^{\circ} \mathrm{C}$ for $30 \mathrm{~s}$, and $72^{\circ} \mathrm{C}$ for $1 \mathrm{~min}$, for 40 cycles. The initial denaturation step was performed at $95^{\circ} \mathrm{C}$ for $10 \mathrm{~min}$. Immediately following amplification, melt curves were created with the cycling parameters of $95^{\circ} \mathrm{C}$ for $15 \mathrm{~s}$, $62^{\circ} \mathrm{C}$ for $1 \mathrm{~min}$, ramping to $95^{\circ} \mathrm{C}\left(0.3^{\circ} \mathrm{C}\right.$ per cycle). The cycling parameters for $v a m p$ were identical, except the annealing temperature used was $60^{\circ} \mathrm{C}$.

\section{RT-qPCR Data Analysis}

sema $2 a$ and vamp products were verified by examination of individual melt curves, and were sequenced to confirm the specificity of the amplicon. The threshold for determining the cycle threshold $\left(\mathrm{C}_{\mathrm{t}}\right)$ was set to 10 times the level of background fluorescence. Samples omitted from further analysis included those with primer dimer formation or average cycle threshold values more than 2 standard deviations from the mean. A Student $t$ test was used to compare mean $1 / C_{t}$ values for each averaged triplicate in control and deafferented tissue, which determined if target expression levels differed between treatment groups.

\section{Results}

We used neuronal tracers and confocal microscopy to confirm and extend our understanding of the deafferentation-induced sprouting that has been previously described [Hoy et al., 1985; Schildberger et al., 1986; Schmitz, 1989]. Figure 2 shows a confocal image of a backfill of an adult control AN-2 (fig. 2a) and one that has been chronically deafferented by removal of the ear on the right (fig. 2b). Alignment of control and chronically deafferented AN-2 along their midlines highlights the obvious qualitative changes in both the medial and lateral parts of the dendritic arbors after deafferentation. For example, the complexity and extent of the lateral dendritic arbor appeared dramatically reduced after deafferentation (arrows, fig. 2). Though the extent of these lateral dendrites varied, the average distance from the midline to the lateral end of the dendritic arbor was significantly shorter after deafferentation $(220.7 \pm 10.1 \mu \mathrm{m}$ in deafferents compared to $311.1 \pm 16.5 \mu \mathrm{m}$ in controls; $\mathrm{n}=5 ; \mathrm{p}=$ 0.0018 ; see figure 5 for further comparisons). Conversely, the dense branches of the medial dendritic arbor (those dendrites within approx. $150 \mu \mathrm{m}$ of the midline) were shifted across the midline via the growth of large dendritic branches towards the contralateral neuropil (arrowheads, fig. $2 b$ ). The contralateral tuft for each neuron is indicated by an asterisk on the left-hand side, but it is only partly reconstructed in the image of the control AN-2 (fig. 2a).

\section{Deafferentation Decreases the Overall Complexity of} the AN-2 Dendritic Arbor

We used a modified Sholl analysis to examine the number of AN-2 dendrites at increasing distances from a point at the midline in control $(n=5)$ and deafferented $(\mathrm{n}=5) \mathrm{AN}-2$ neurons. Concentric rings, spaced at approximately $5 \mu \mathrm{m}$, were centered on the point where the primary neurite crossed the midline (fig. 3a). Points of dendritic intersections with each ring were marked, and the left and right halves were tallied separately (fig. 3b). When we compared all data points on the left and right sides, there was a significant interaction between side and deafferentation $[\mathrm{F}(1,8)=139 ; \mathrm{p}<0.000001]$, so each side was analyzed separately. We chose to define medial dendrites as those scored in rings $1-33$, and lateral dendrites as those scored in rings 34-60. We used 'distance from the midline' (medial vs. lateral) as a within-subjects variable in our subsequent analyses. Upon analyzing the right side alone, we found that deafferentation significantly reduced the complexity of both medial and lateral dendrites, as evidenced by a significant main effect of treatment $[\mathrm{F}(1,8)=91.7 ; \mathrm{p}=0.00001]$, but no interaction between treatment and distance $[\mathrm{F}(1,8)=2.92 ; \mathrm{p}=0.12]$. As was evident in the graph, the medial dendrites were more complex than the lateral dendrites $[\mathrm{F}(1,8)=91.4 ; \mathrm{p}=$ 0.00001]. Analysis of the contralateral side (left side of graph in fig. $3 \mathrm{~b}$ ) indicated there was significantly more complexity in the deafferented neurons as compared to controls $[\mathrm{F}(1,8)=77.6 ; \mathrm{p}=0.00002]$. 

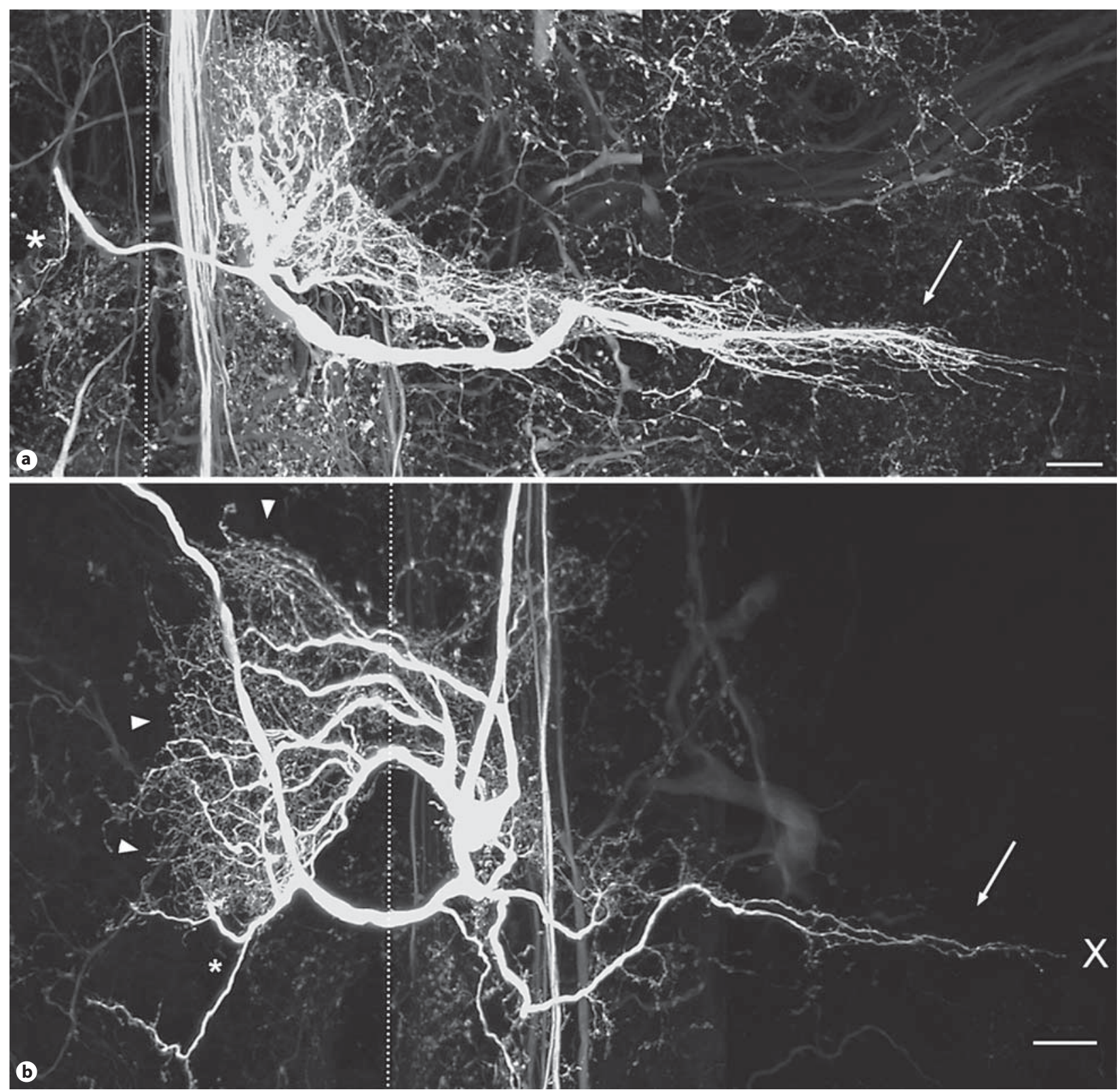

Fig. 2. Alignment of control and deafferented AN-2 revealed qualitative changes of the medial and lateral dendrites. Dotted line: midline. Arrows: alterations in the extent and complexity of the lateral dendrites. Asterisks: contralateral tuft. The image is a projection of 71 optical sections. Scale bars $=20 \mu \mathrm{m}$. a Confocal im- age of a biocytin-backfilled control AN-2. The image is a twodimensional projection of 76 optical sections. b Confocal image of a biocytin-backfilled AN-2 that was chronically deafferented on the right. $\mathrm{X}=$ Deafferented side. Arrowheads: compensatory growth of the dendrites across the midline.
Though most of the complexity of the left side of figure $3 \mathrm{~b}$ was obviously due to the large number of dendrites which sprouted across the midline, we wanted to see if expansion of the contralateral tuft after deafferentation also contributed. Therefore, the contralateral dendritic branch was analyzed separately in control and deaffer- ented AN-2 (fig. 3c). We found that deafferentation did not significantly affect the complexity of this dendritic branch as compared to controls $(\mathrm{p}=0.259)$, implying that the large increase in dendritic complexity seen on the lefthand side in figure $3 \mathrm{~b}$ was exclusively due to dendrites growing across the midline after deafferentation. 


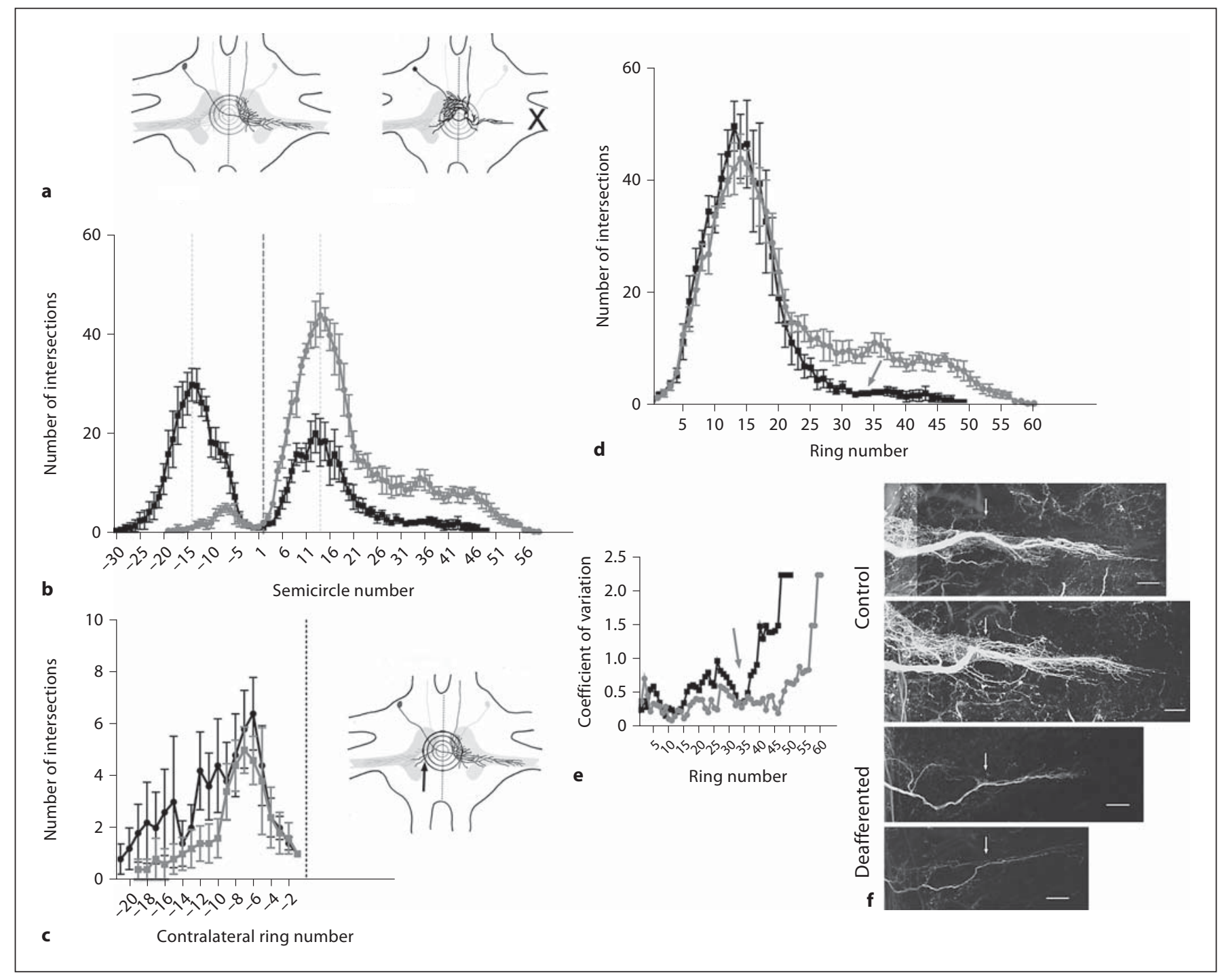

Fig. 3. Quantification of the effects of deafferentation on AN-2 dendrites. a Schematic of the Sholl analysis performed on control (left) and deafferented ganglia (right). Concentric rings were centered on the midline point of the primary neurite. $\mathbf{b}$ Sholl analysis of control (gray dots) and deafferented (black squares) dendrites. Intersections of dendritic branches per semicircle (left and right side tallied separately) are plotted as average \pm SEM. Dark dashed line: midline. Lighter dashed lines: symmetrical peaks in complexity. c Sholl analysis of the contralateral tuft was analyzed separately. Arrow on schematic: this dendritic branch. d Overall

It was striking that dendrites tended to grow in a symmetrical pattern after deafferentation, with the mirror image peaks in complexity centered roughly at ring number 14 (dotted lines, fig. 3b). To determine whether the overall complexity of the dendrites was similar before and after deafferentation, we combined the measurements measurement of dendritic complexity, where the number of intersections per semicircle was combined into a single ring. Arrow: region of low variability at approximately ring 34 . e Plot of the coefficient of variation for control (gray dots) and deafferented dendrites (black squares). Arrow: sharp drop in coefficient of variation. $\mathbf{f}$ To examine the morphology of the dendrites within the region of low variability, images were aligned along their midlines. Arrows: location of ring 34, which is approximately $170 \mu \mathrm{m}$ from the midline. Scale bars $=20 \mu \mathrm{m}$.

from both sides of the Sholl analysis (fig. 3d). A repeated measures ANOVA with 'distance from the midline' as a within-subjects variable and 'treatment' as a betweensubjects variable indicated that deafferentation significantly decreased the overall complexity of dendrites $[\mathrm{F}(1$, $8)=77.88 ; p=0.023]$, and no interaction of distance with 

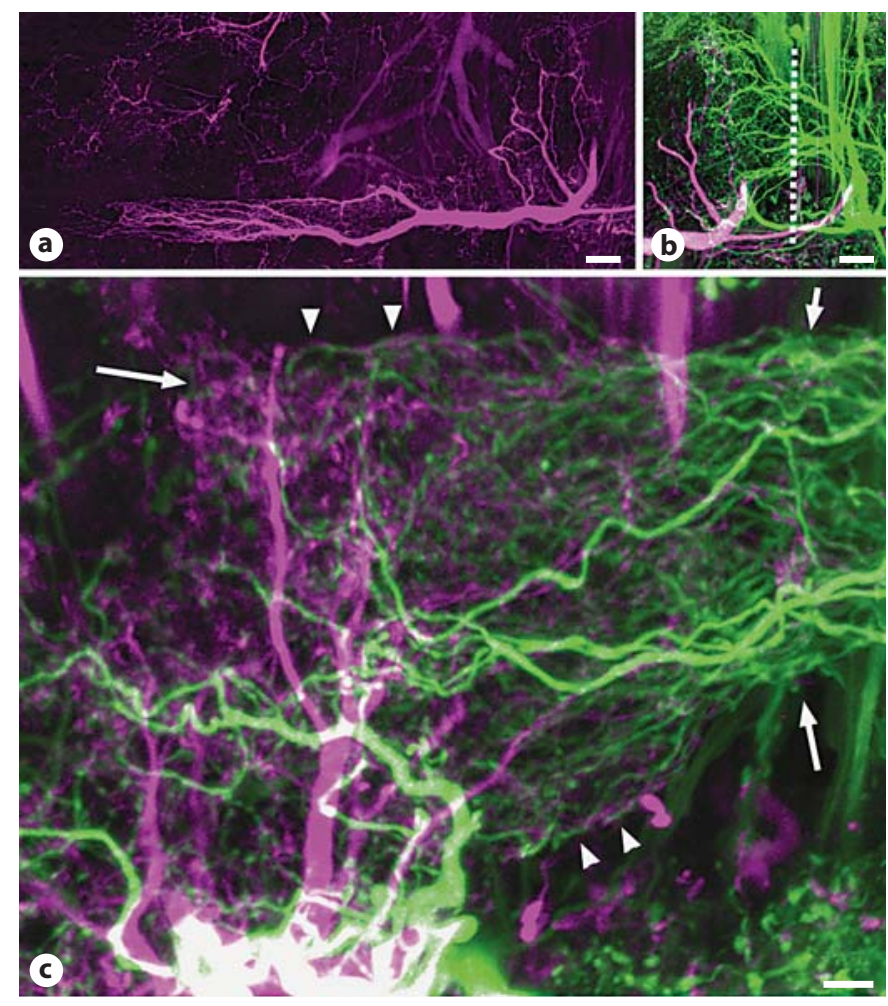

Fig. 4. Confocal images exploring the overlap of nonafferented AN-2 dendrites on the intact side (magenta) and deafferented AN-2 dendrites (green) in double-labeled ganglia. a, b Scale bars $=20 \mu \mathrm{m}$. c, $\mathbf{d}$ Scale bars $=5 \mu \mathrm{m}$. a Confocal projection of the AN-2 contralateral to deafferentation demonstrates a qualitatively normal morphology. The midline is at the far right. b Doublelabeling of the magenta cell as in a along with the deafferented

deafferentation was evident $[\mathrm{F}(1,8)=0.65 ; \mathrm{p}=0.4429]$. Thus, despite the extensive growth of dendrites across the midline, the overall dendritic complexity was significantly lower in deafferented AN-2 neurons than in the control.

We also noted a region of noticeably decreased variability in branch number for both conditions centered at ring 34 (or approx. $170 \mu \mathrm{m}$ from the midline), though it was especially obvious for deafferented AN-2 (arrow, fig. 3d). This reduction in variability could be examined more readily by calculating the coefficient of variation (fig. 3e), and a sharp dip centered at ring 34 can be seen (arrow, fig. 3e). Image montages of control and deafferented AN-2 were aligned at the midline and cropped to show the lateral-most dendrites (fig. 3f). The point approximately $170 \mu \mathrm{m}$ from the midline in each dendritic arbor is noted with an arrow (fig. 3e), which is where the variability in the number of dendritic branches decreased most obviously in deafferented dendrites.

Cellular and Molecular Consequences of Deafferentation

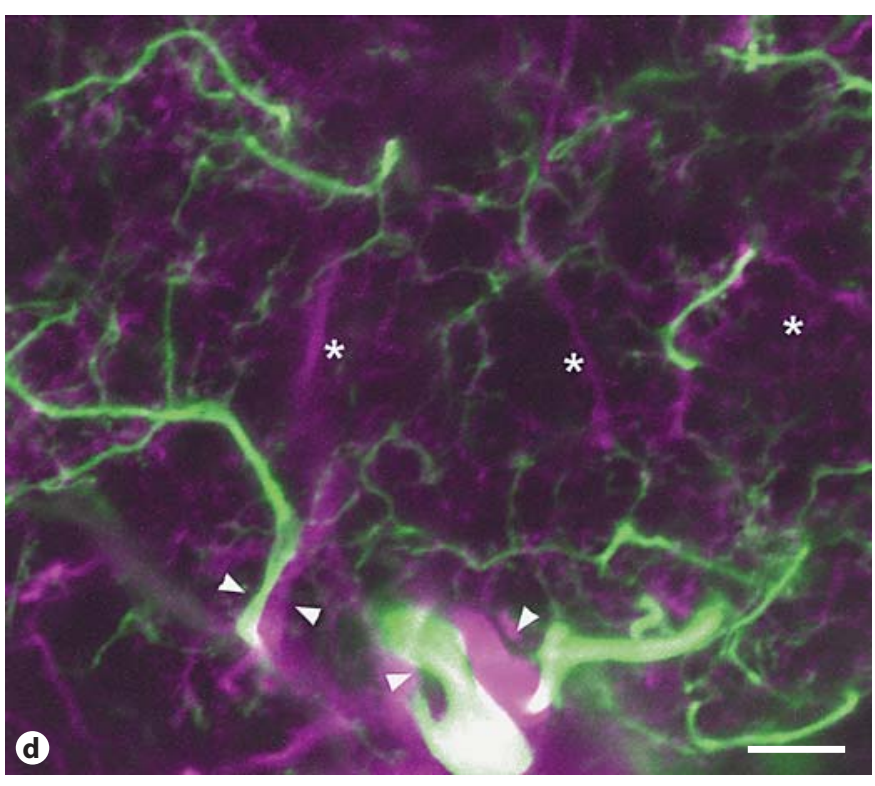

AN-2 (green). Dotted line: midline. c At some locations, both sets of dendrites appear to respect similar boundaries (arrowheads). Arrows: regions where one set of dendrites or the other predominates. The midline is to the right. $\mathbf{d}$ A single optical section reveals that dendrites from each pair grew in close apposition (arrowheads). Asterisks: regions where one set of dendrites was predominant (magenta). The midline is to the right.

\section{Cellular Consequences of Deafferentation for the}

Mirror-Image, Intact AN-2

Past experiments have indicated that while the physiological and cellular changes in the deafferented AN-2 are obvious, its mirror image partner is neurophysiologically unaffected by the removal of the opposite ear and subsequent invasion of new dendrites into the medial portion of its dendritic arbor [Brodfuehrer and Hoy, 1988]. Given the extent of the deafferentation-induced dendritic ingrowth observed in some cases, one might expect some form of dendritic rearrangement of the contralateral AN-2 dendrites or partitioning of separate dendritic territories to accommodate the compensatory growth. Qualitative examination of the gross morphology of the dendritic arbor did not reveal any obvious changes after chronic deafferentation (fig. 4a). Doublelabeling both the deafferented AN-2 (green) and nondeafferented $\mathrm{AN}-2$ from the intact side (magenta) in a single

Dev Neurosci 2011;33:21-37 


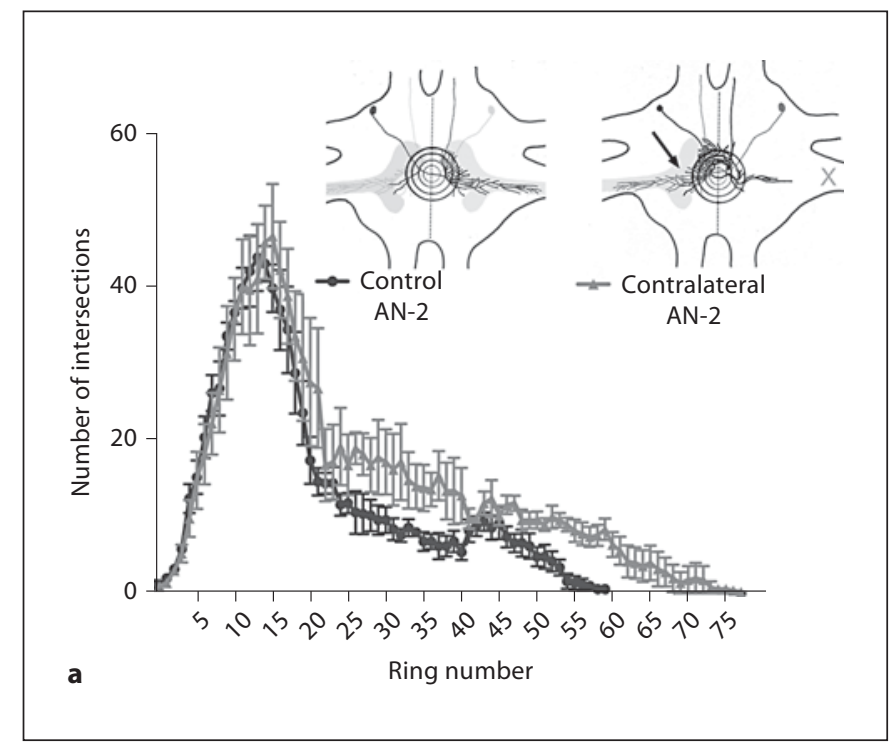

Fig. 5. Quantification of the effects of deafferentation on the contralateral (nondeafferented) AN-2. a Sholl analysis examining the number of dendritic intersections per ring for control AN-2 (black dots) as compared to the AN-2 contralateral to deafferentation (light gray triangles) plotted as average \pm SEM. Inset Schematic of concentric rings placed on the midline of the primary neurite to measure the dendrites of the control AN-2 (left) and the AN-2 contralateral to deafferentation (right). $\mathrm{X}=$ Side of deafferent-

ganglion revealed the extent to which these arbors overlapped (fig. 4b). Small stacks of optical sections from different pairs of cells revealed no obvious partitioning or tiling of the contralateral (nondeafferented) dendrites in the presence of these new processes (fig. 4c, d). Instead, there were obvious examples of the two sets of dendrites growing in close apposition with one another (arrowheads, fig. $4 \mathrm{~d}$ ) and respecting similar boundaries (arrowheads, fig. 4c). However, we also noted areas where one type of dendrite or the other appeared more predominant (arrows, fig. 4c; asterisks, fig. 4d), though this was rarely unequivocal. This was, of course, especially true closer to the midline, where the ingrowth from the deafferented AN-2 was dominant (rightmost arrows, fig. 4c).

To confirm the lack of anatomical changes in the intact AN-2 after chronic deafferentation, we performed a modified Sholl analysis on these neurons in the adult and compared them to controls (insets, fig. 5a). There was no overall effect of contralateral deafferentation on dendritic complexity in the nondeafferented AN-2 $(\mathrm{n}=5)$ as compared to controls $[\mathrm{n}=5 ; \mathrm{F}(1,8)=2.24 ; \mathrm{p}=0.172]$. However, we were surprised to find a significant increase in the overall length of the dendritic arbor. While deaf-

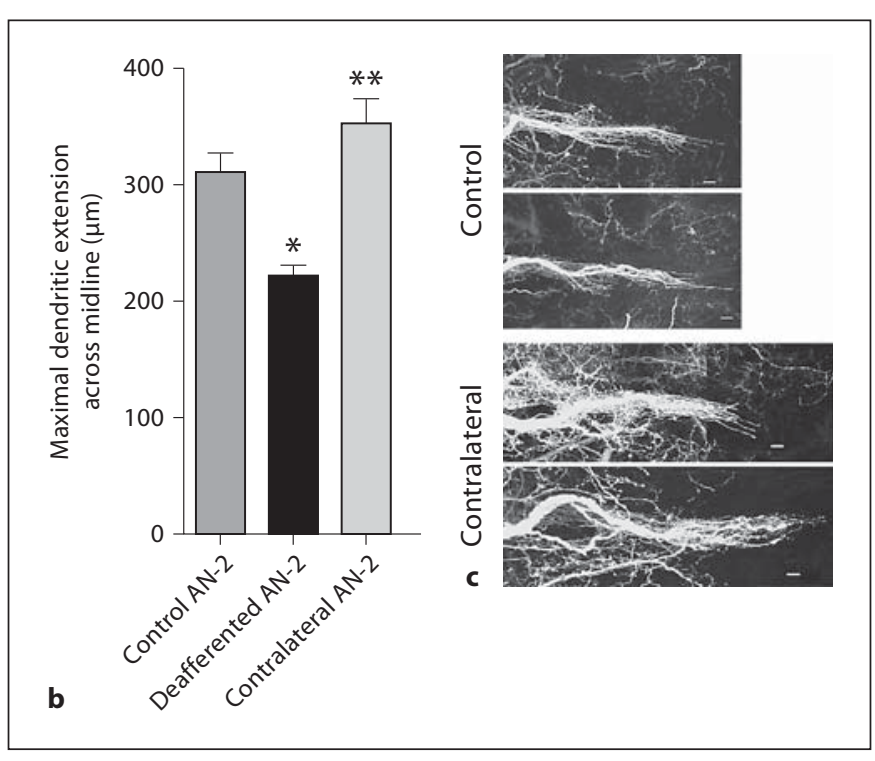

ation. Arrow: contralateral AN-2 measured in this case. b Length of the extent of the lateral dendritic arbor for control, deafferented and contralateral (nondeafferented) AN-2, plotted as average \pm SEM. Asterisks: significant differences in dendritic length as compared to control. c Images were aligned along their midlines and cropped to show differences in the extent of control dendrites and dendrites from the AN-2 contralateral to deafferentation. Scale bars $=10 \mu \mathrm{m}$.

ferented AN-2 were on average $90 \mu \mathrm{m}$ shorter than control AN-2 (above), the AN-2 contralateral to deafferentation were significantly longer ( $\mathrm{p}=0.0018$; fig. 5b). Visual inspection of aligned images of the lateral dendrites from control AN-2 neurons and AN-2 neurons contralateral to deafferentation made the increased length and 'bushiness' of these lateral dendritic branches obvious (fig. 5c). Finally, though the lateral AN-2 dendrites on the intact side apparently grew in response to contralateral deafferentation which was centered hundreds of micrometers away, this change appeared isolated as there was no evident alteration in dendritic growth closer to the deafferented area (i.e. for medial dendrites in fig. 5a). In addition, there was no significant increase in the number of dendrites crossing the midline in the nondeafferented AN-2 $(6.4 \pm 2.94)$ as compared to controls $(3.4 \pm 0.92 ; \mathrm{p}=$ 0.194; data not shown).

\section{Effects of Unilateral Deafferentation on the Contralateral Auditory Afferents}

After deafferentation, left and right $\mathrm{AN}-2$ both receive input from the remaining auditory afferents [Hoy et al., 1985; Schildberger et al., 1986]. We wished to explore the 
cellular consequences of deafferentation on these intact auditory axons (contralateral to deafferentation). Though the changes in these afferents have been examined after adult deafferentation, the effects of chronic deafferentation throughout larval development have never been examined in detail. In order to visualize the afferents themselves as well as their anatomical relationship with the contralateral AN-2 dendrites, we performed double-labeling experiments (fig. 6a, e). The auditory axons of control animals typically grew up to the midline area but did not overlap substantially with the contralateral AN-2 dendrites (fig. 6b). While there was some variability in the shape and extent of auditory afferent arbors in control ganglia, the bulk of the axons remained on the ipsilateral side of the midline (fig. 6c, d). However, occasional axons were observed to cross the midline in control ganglia (arrow, fig. $6 \mathrm{~d}$ ). There were obvious qualitative changes in the neuropil shape and length after deafferentation of the contralateral auditory afferents (fig. $6 \mathrm{f}-\mathrm{h}$ ). Most obvious was an increase in the number and extent of axons growing across the midline (arrows, fig. $6 \mathrm{f}-\mathrm{h}$ ), and the neuropil often appeared narrowed and thinner than in controls (fig. $6 \mathrm{~g}, \mathrm{~h}$ ). In addition, the boundaries of the neuropil appeared less well defined, and we typically noticed a number of small axonal branches projecting out of the neuropil (arrowheads, fig. 6g).

Quantification of control axons (fig. 7a) and those contralateral to deafferentation (fig. $7 \mathrm{~b}$ ) indicated that more axons crossed the midline in deafferented ganglia $(11.0 \pm 0.89 ; \mathrm{n}=6$ ganglia) than in controls $(4.2 \pm 1.84$; $\mathrm{n}=9$ ganglia), a difference that was statistically significant ( $p=0.014$; data not shown). In addition, these axons extended significantly farther from the midline in deafferents than in controls $(p<0.0001$; fig. $7 c)$. Consistent with these results, the volume of axonal processes on the contralateral side of the midline was also significantly greater in deafferented ganglia than in controls ( $\mathrm{p}=$ 0.026; fig. 7d).

While these changes were significant, they were still fairly subtle and may not have been sufficient to compensate for the increased postsynaptic demand after deafferentation. Therefore, we also quantified changes in the number and size of presynaptic sites. Varicosities detectable at the light microscope level (arrows, fig. 7e, f) have been determined to represent synaptic sites [Hardt and Watson, 1999]. Therefore, we measured the density and volume of these varicosities in controls (3,688 varicosities in 4 ganglia) (fig. 7e) and deafferented ganglia (9,778 varicosities in 6 ganglia) (fig. 7f). Neither the density ( $\mathrm{p}=$ 0.209 ) (fig. $7 \mathrm{~g}$ ) nor the volume ( $\mathrm{p}=0.699$ ) (fig. $7 \mathrm{~h}$ ) of var-

Cellular and Molecular Consequences of Deafferentation icosities changed significantly after deafferentation when assessed at the light microscope level. We also measured the total axonal volumes (fig. 7i) as well as the total number of varicosities per image (fig. 7j). Neither the volume $(p=0.178)$ nor the total number of varicosities $(p=0.1273)$ were significantly different. However, our results indicate that there may be a trend towards more axonal volume and an increased number of varicosities after deafferentation, which would be consistent with a compensatory response of the presynaptic axonal terminals.

Finally, we wished to explore the cellular relationship between the auditory axons and AN-2 dendrites under control (fig. 8a) and deafferented (fig. 8e) conditions to determine if there were qualitative differences. In control ganglia, there was generally a fairly tight overlap between auditory axons and AN-2 dendrites. Both axons and dendrites typically observed the same boundaries (arrows, fig. $8 \mathrm{~b}, \mathrm{c}$ ). There were examples of small axonal projections outside the main neuropil region in control ganglia (arrowhead, fig. 8b), but these were not common. We frequently observed examples of tight apposition between axons and dendrites (arrowheads, fig. 8c). The dendrites often formed rounded or looped shapes (arrowheads, fig. 8d), though the centers of these loops were not usually associated with a dye-filled axonal process.

After deafferentation, there appeared to be some differences in the morphological relationship between auditory axons and AN-2 dendrites. First, due to the increased amount of axonal processes crossing the midline, more overlap was observed on the opposite side of the midline from the intact auditory afferents (region depicted by the top arrow in fig. 8e) in deafferented ganglia (fig. 8f, g). In the particular example shown in figure $8 \mathrm{f}$, and at higher power in figure $8 \mathrm{~g}$, the axons and dendrites in this region appeared to grow in close apposition (arrowheads, fig. 8g), with axons sometimes surrounding dendrites or dendrites sometimes looping around axons. We also found that the deafferented dendrites sent numerous projections to areas outside the main axonal arbor (fig. 8i). Since we commonly observed axons projecting outside of the neuropil in deafferented ganglia (arrowheads, fig. $8 \mathrm{~h}$, and above), this appeared to be a region in which deafferented dendrites and axons could grow in close apposition (merged images, fig. 8j), without disrupting the normal synapses between ipsilateral axons and AN-2 dendrites.

\section{Differential Regulation of vamp and sema2a in}

Response to Deafferentation

RT-qPCR was performed to gain a preliminary understanding of the molecular underpinnings of deafferenta- 

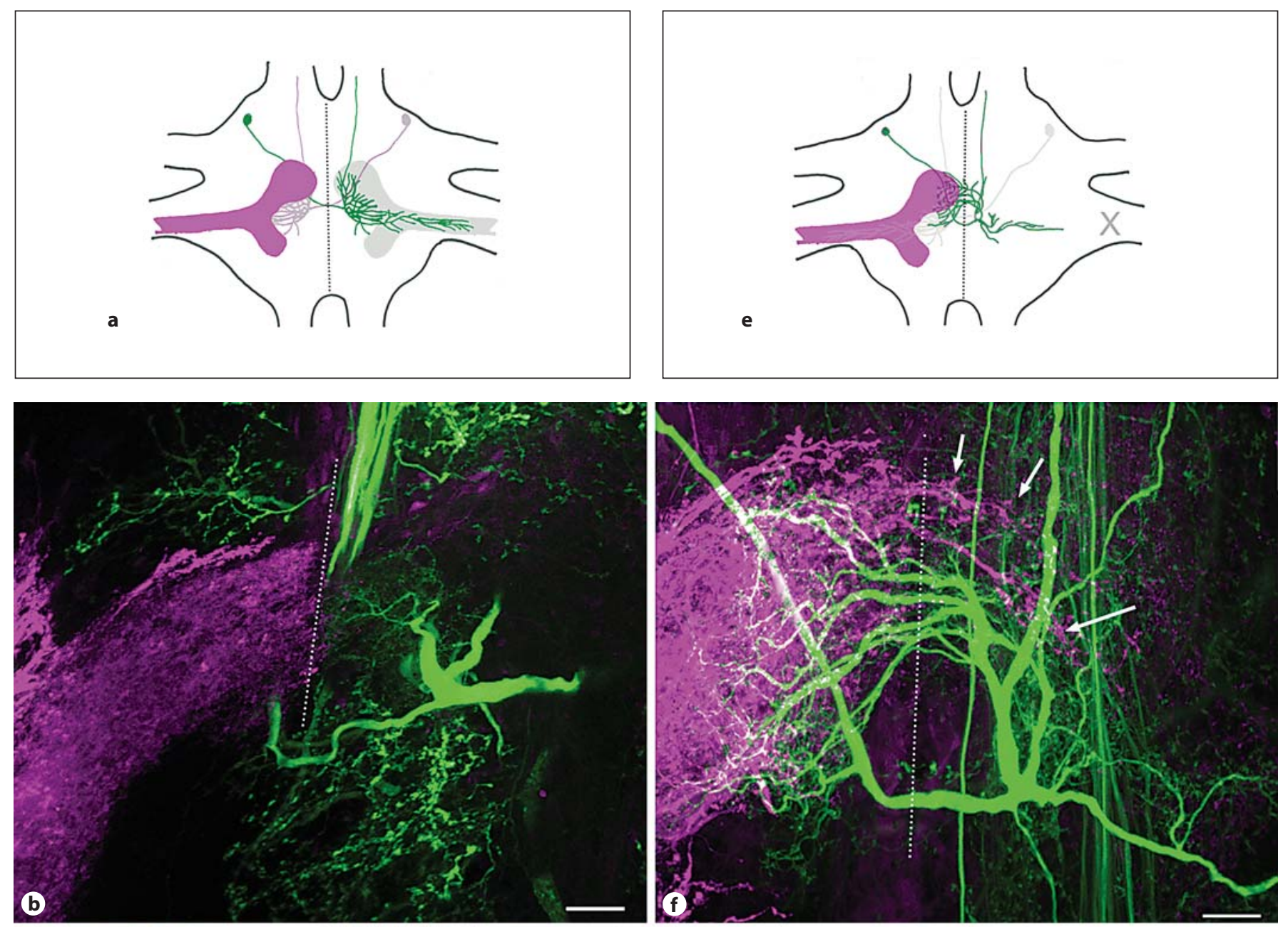
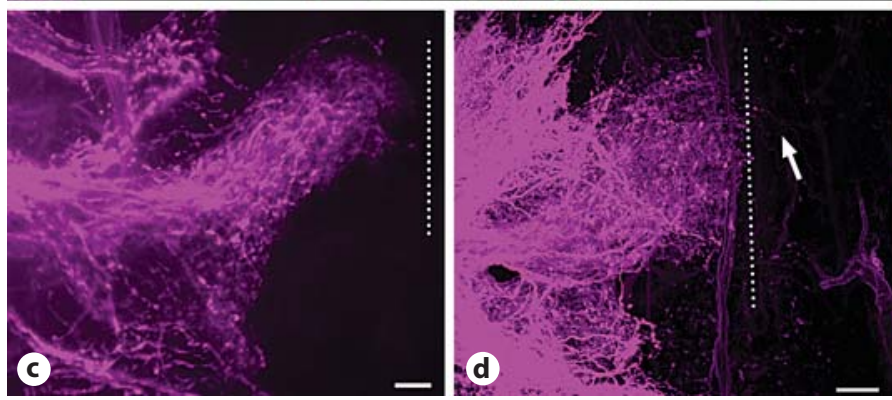

Fig. 6. Confocal images exploring the growth about the midline for AN-2 dendrites (green) and auditory afferents (magenta) in control (a-d) and deafferented ganglia (e-h). Scale bars $=20 \mu \mathrm{m}$. a Schematic of double-labeled control ganglia. This type of double-labeling was used in $\mathbf{b}-\mathbf{d}$. $\mathbf{b}$ Confocal image of double-labeled ganglia revealing that auditory afferents grow up to the midline (dotted line) but overlap very little with the dendrites of the contralateral AN-2. This image shows a subsection of the AN-2 for clarity. c, d Two examples of the auditory neuropil in control ganglia. Most axons respect the midline, though a few axons do grow over (arrow, d). e Schematic representation of the double-labeled

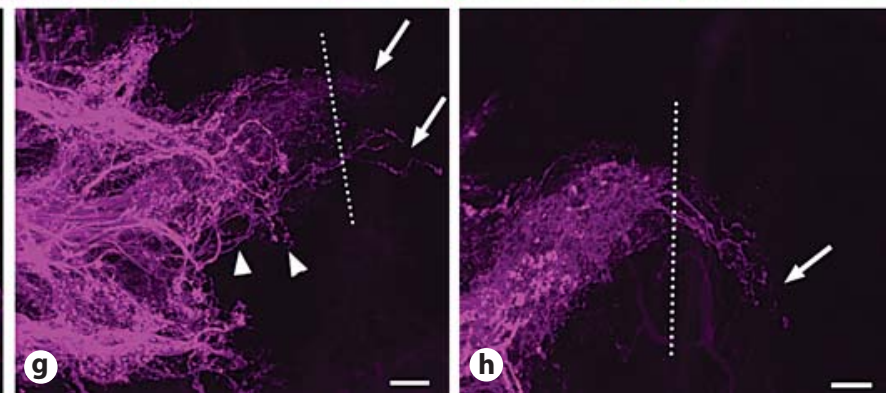

deafferented ganglia. Deafferentation was on the right (as indicated by the X), deafferented dendrites are green, and the remaining contralateral auditory afferents are magenta. This type of double-labeling was used in figures $\mathbf{f}-\mathbf{h}$. $\mathbf{f}$ Confocal image at the midline of a deafferented ganglion shows robust growth across the midline of both dendrites and axons. Arrows: contralateral projections of auditory afferents. $\mathbf{g}, \mathbf{h}$ Two examples of the auditory neuropil from deafferented ganglia. Axons crossing the midline (dotted line) were commonly seen (arrows). Arrowheads: axons projecting out of the boundaries of the auditory neuropil. 

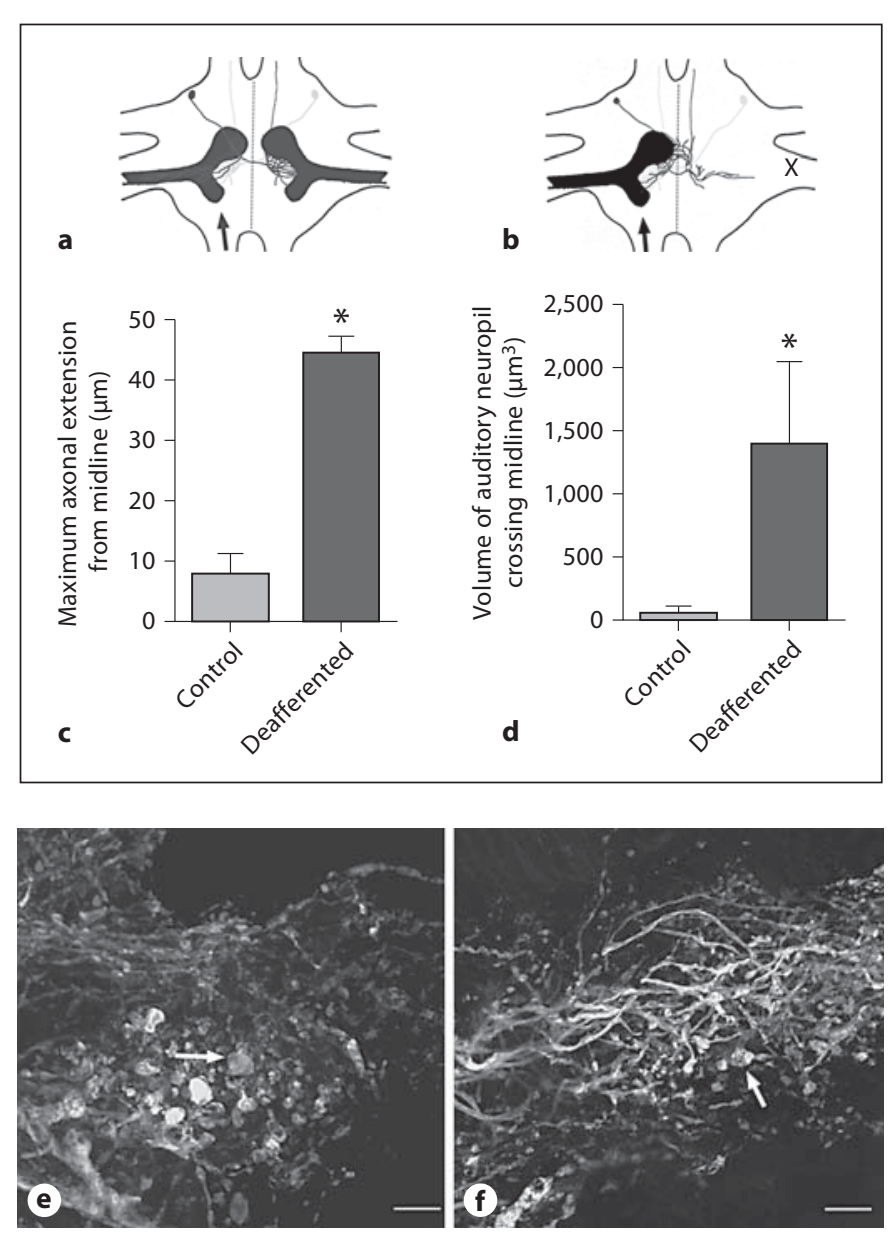

Fig. 7. Quantification of the effects of deafferentation on the contralateral, intact auditory afferents. a Schematic of the auditory afferents backfilled in control ganglia (arrow). b Schematic of the auditory afferents backfilled in deafferented ganglia. $\mathrm{X}=$ Side of deafferentation. Afferents quantified were contralateral to the deafferentation (arrow). c Quantification of the maximum amount of axonal extension across the midline for control auditory afferents and the intact auditory afferents in deafferented ganglia. Asterisk: statistical significance ( $t$ test). d Quantification of the volume of auditory neuropil found across the midline in control and intact auditory afferents in deafferented ganglia. Asterisk: statis-

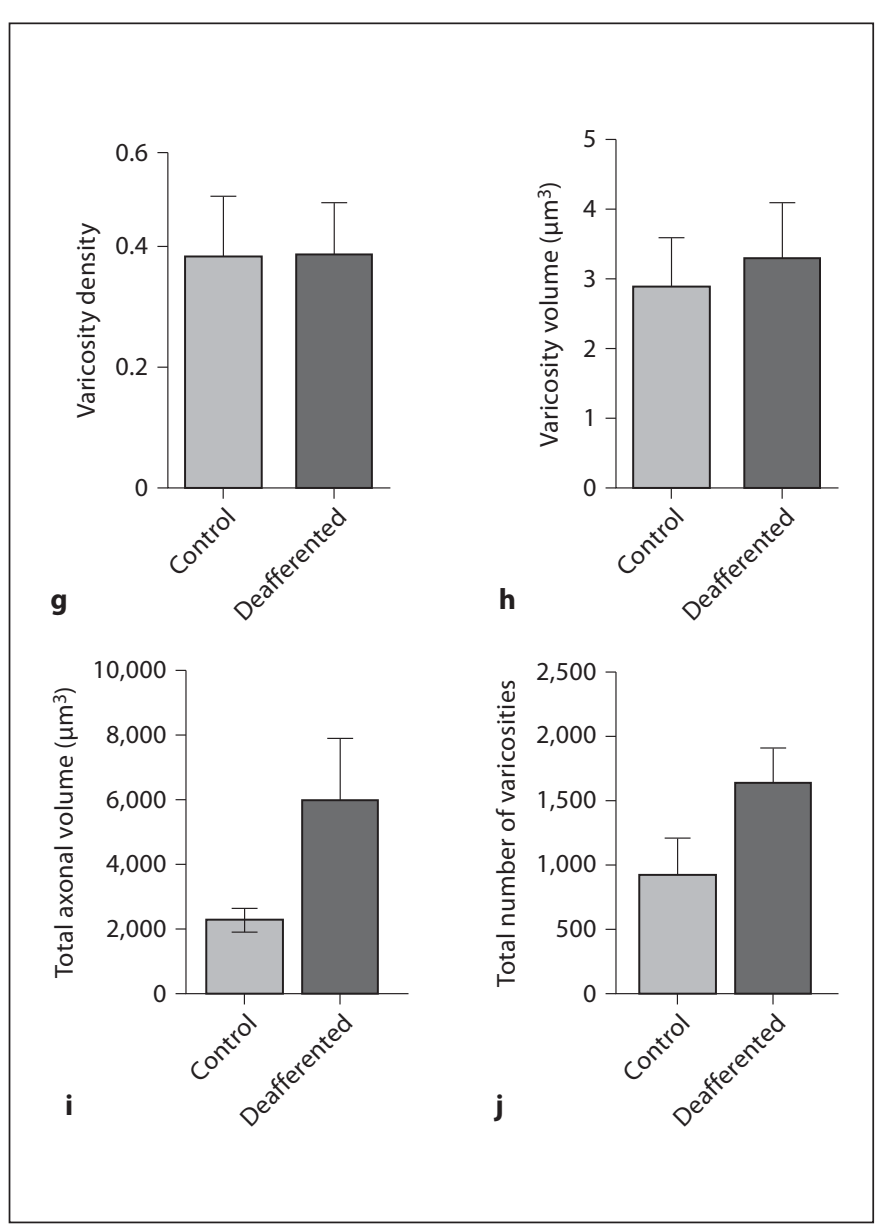

tical significance ( $t$ test). e, $\mathbf{f}$ Varicosities (arrows) can be seen in backfilled afferents in control ganglia (e) and deafferented ganglia (f). Scale bars $=10 \mu \mathrm{m}$. The midline is on the right in both. g Average ( \pm SEM) varicosity density in auditory afferents in control ganglia (gray) and deafferented ganglia (black). $\mathbf{h}$ Average ( \pm SEM) volume of varicosities in control ganglia (gray) and deafferented ganglia (black). i Average ( \pm SEM) total axonal volume in control ganglia (gray) and deafferented ganglia (black). j Average $( \pm$ SEM) total number of varicosities identified in control ganglia (gray) and deafferented ganglia (black). tion. We purified mRNA and made cDNA from individual ganglia in order to assess the relative levels of two transcripts, vamp and sema2a, in each ganglia. On average, levels of these transcripts expressed in the prothoracic ganglia changed significantly in response to deafferentation, though in different directions for each transcript (fig. 9). The mean vamp $1 / \mathrm{C}_{\mathrm{t}}$ value for deafferented ganglia was significantly lower than that of control ganglia $[t(8)=2.30 ; p=0.05]$ (fig. 9), indicating a significant downregulation of vamp upon deafferentation. Conversely, the mean sema2a $1 / C_{t}$ value was significantly higher in deafferented ganglia than in controls, indicating an upregulation of sema2a in deafferented animals $[\mathrm{t}(12)=1.86 ; \mathrm{p}=0.04]$. It is important to note that since we consistently saw an upregulation of sema2a in our in situ hybridization experiments (data not shown), we expected an increase and performed a one-tailed, unpaired $\mathrm{t}$ test on the sema2a data. 

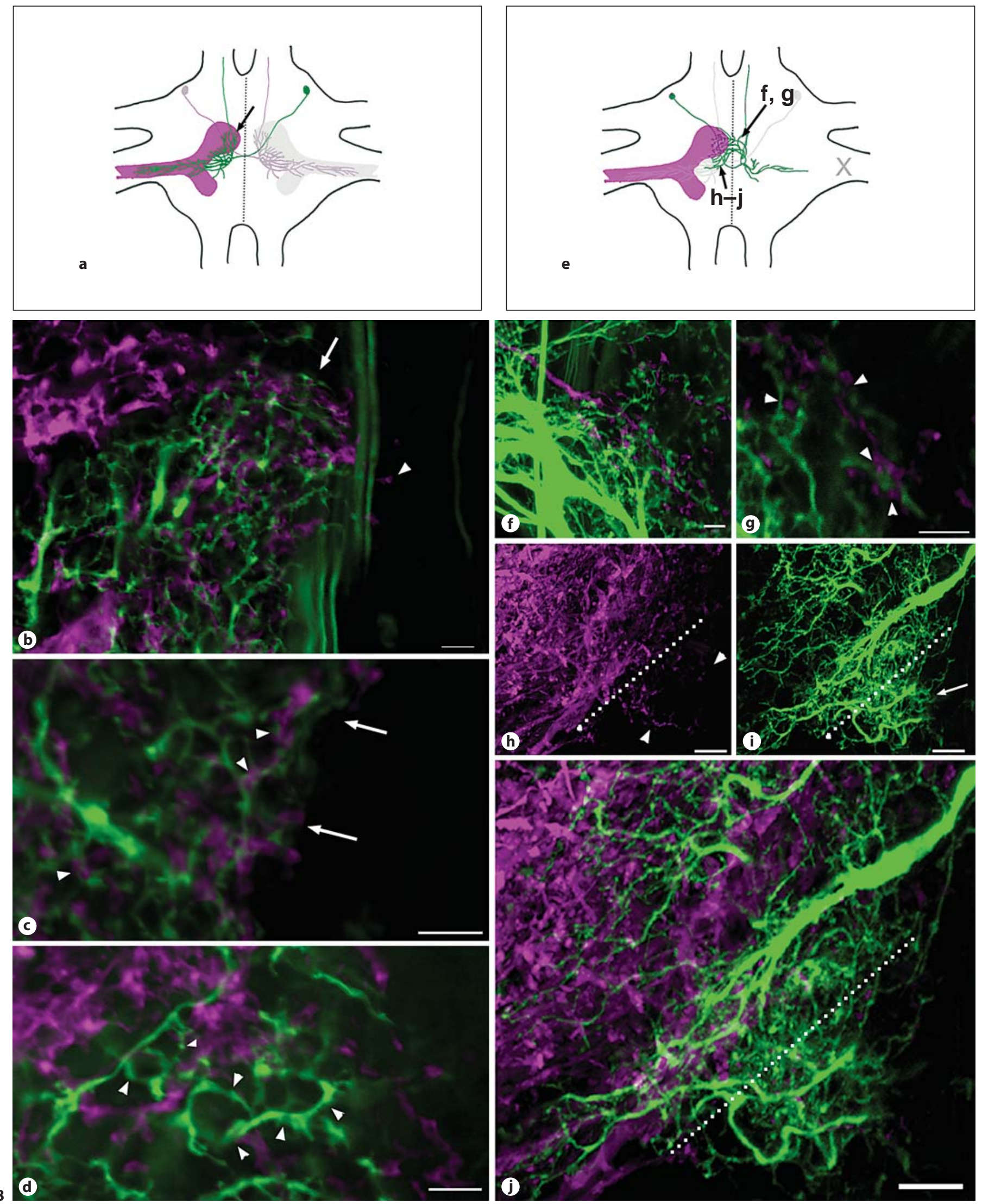


\section{Discussion}

Our results confirm and extend previous work examining the consequences of deafferentation in the cricket. In particular, we show that three separate components of the auditory system on both sides of the ganglia were morphologically altered by chronic, unilateral deafferentation. We have confirmed and quantified aspects of $\mathrm{AN}-2$ response to deafferentation, such as the decrease in the length of the lateral dendrites and the overall decrease in dendritic complexity. Intriguingly, we have also shown that deafferented AN-2 dendrites, while capable of ignoring some boundaries such as the midline, respected others (fig. 4c). The changes in axonal growth after chronic deafferentation of the contralateral afferents have been quantified here for the first time as well. Most surprisingly, we have shown that deafferentation induced the intact AN-2 dendrites from the contralateral side to extend laterally away from the denervated side. Presumably, the

Fig. 8. Confocal images exploring the overlap between AN-2 dendrites (green) and auditory afferents (magenta) in control (a-d) and deafferented ganglia (e-j). $\mathbf{b}-\mathbf{g}$ Scale bars $=5 \mu \mathrm{m}$. $\mathbf{h}-\mathbf{j}$ Scale bars $=10 \mu \mathrm{m}$. a Schematic of the double backfills used in images b-d to explore the overlap of auditory afferents and AN-2 dendrites in the auditory neuropil region (arrow) of control ganglia. The midline is on the right in images $\mathbf{b}-\mathbf{d}$. $\mathbf{b}$ Confocal image revealing a significant overlap (arrow) of auditory afferents and AN-2 dendrites in control ganglia. Arrowhead: axons projecting out of the main neuropil region. c Higher-power image revealing that dendrites and axons often grew in close apposition to each other in this region (arrowheads). Axons and dendrites also both seemed to respect a similar boundary in controls (arrows). d Dendrites often grew in looped structures (arrowheads). The centers of these loops were usually devoid of magenta axons. e Schematic of the double backfills used in images $\mathbf{f}-\mathbf{j}$ to explore the overlap of auditory afferents and deafferented AN-2 dendrites. $\mathrm{X}=$ Deafferentation on the right. As indicated by the arrows, the images in $\mathbf{f}$ and $\mathbf{g}$ focus on the region just contralateral to the auditory afferents, and the images in $\mathbf{h}-\mathbf{j}$ on the edge of the auditory neuropil. f Axons which crossed over the midline (left of image) after deafferentation grew through the sprouted AN-2 dendrites. g Higherpower image of this region showing that axons and dendrites grew in close apposition here (arrowheads). $\mathbf{h}$ Small axonal branches (arrowheads) projected out of the main auditory neuropil. Dotted line: rough boundary. The midline is on the right side of the image. $\mathbf{i}$ The same region as shown in $\mathbf{h}$, but showing the projection pattern of the dendrites. Arrow: many AN-2 dendrites which projected outside of the auditory neuropil (dotted line). $\mathbf{j}$ Merging of images $\mathbf{h}$ and $\mathbf{i}$ indicating that deafferented AN-2 dendrites projected both in the main auditory neuropil as well as outside the neuropil (dotted line).

Cellular and Molecular Consequences of Deafferentation axons and dendrites contralateral to deafferentation were affected indirectly or secondarily by the unilateral loss of auditory input. All of these novel results define parameters of deafferentation-induced growth that must be taken into account as we search for the molecular cues which induce or facilitate these morphological changes [Horch et al., 2009]. As a preliminary step in this search, we have also shown that vamp and sema $2 a$ are differentially regulated upon deafferentation, indicating that transcriptional changes in well-conserved genes may play a role in the anatomical changes.

\section{Direct Effects of Deafferentation on Ipsilateral AN-2 \\ Dendrites}

Overall, deafferentation induced a significant reduction in complexity of the ipsilateral AN-2 dendrites. While the complexity of the medial dendrites on the deafferented AN-2 was greatly reduced on the deafferented side, this was roughly balanced by the new growth of dendrites across the midline into the contralateral neuropil. Why do some dendrites within a single neuron respond differently to loss of input than others? In fact, the dendrites closer to the midline are thought to be functionally different from the more lateral branches [Hardt and Watson, 1994; Hirtz and Wiese, 1997], implying that functionally distinct dendritic compartments may be responding differently to deafferentation. Differential responses to deafferentation of individual portions of the dendritic arbor have been noted before. Removal of the cerci of the cockroach alters the morphology of postsynaptic dendrites, and these changes are most evident in the distal and higherorder branches [Mizrahi and Libersat, 2002].

The reduction in lateral dendritic complexity noted here has been described before [Hoy et al., 1985; Schildberger et al., 1986], though never quantified. We wondered whether this loss in complexity was quantitatively balanced by the new growth across the midline. Observations in a variety of species have led to the hypothesis that each neuron is predetermined to be a particular size [Schneider, 1973; Devor, 1975]. For example, axotomy or changes in afferent innervation induce changes in dendritic arbors that appear to be balanced by reciprocal changes in other regions [Shankland et al., 1982; Roederer and Cohen, 1983; Hall and Cohen, 1988]. Our results indicated an overall decrease in dendritic complexity, and one could speculate that the total volume was thus reduced after deafferentation as well. Sholl analysis, however, is obviously an imperfect substitute for complete volume measurements and would be insensitive to an increase in the number of very short dendritic branches $(<5$ 


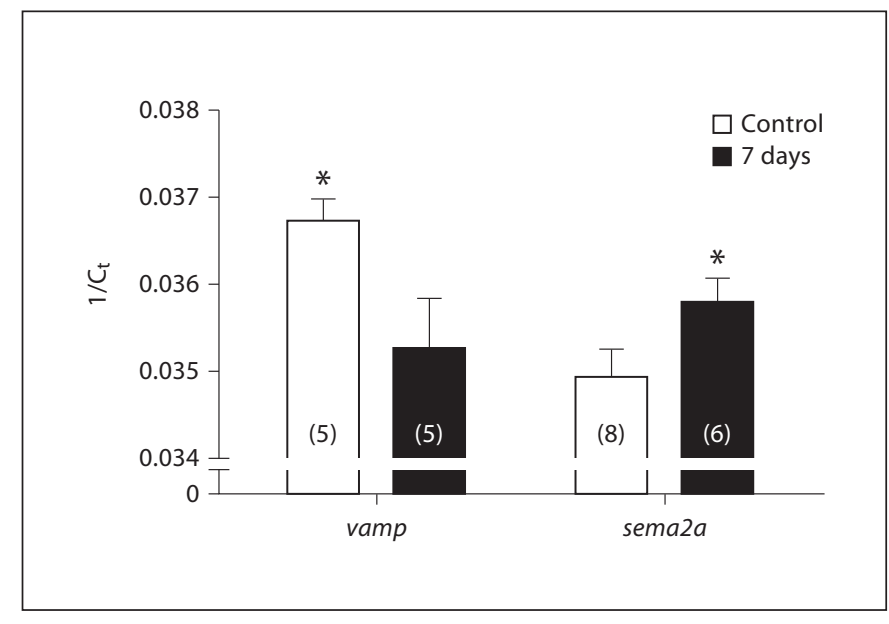

Fig. 9. RT-qPCR results of vamp and sema2a expression in the prothoracic ganglia of 7-day deafferented adults (black bars) and control crickets (white bars). RT-qPCR revealed a decreased expression of vamp and an increased expression of sema2a in 7-day deafferented ganglia as compared to control ganglia. Data are presented as $1 / C_{t}$ so that changes more intuitively represent changes in expression levels. Numbers in parentheses at the base of the bars: number of individual ganglia compared. Error bars: SEM. Melt curves showed single peaks at the predicted melting temperature (data not shown) indicating single product amplification, which was subsequently confirmed by sequencing. Standard curves created using dilution series of cDNA ranging from 1:4 to 1:512 showed correlation values $\left(\mathrm{R}^{2}\right)$ above 0.9 and primer efficiencies between 90 and $110 \%$ (data not shown) indicating suitable reagent concentrations. All negative controls, including notemplate and templates without reverse transcriptase, did not amplify, thus confirming a lack of DNA contamination.

$\mu \mathrm{m}$ long) or to changes in branch diameter. The loss of volume due to a reduction in branch number could potentially be compensated for by an increase in the diameter of a few, large dendritic branches. However, the results presented here predict that volume measurements of individually labeled AN-2 before and after deafferentation would show a decrease in overall volume, and that the auditory system of the cricket appears to be an ideal system in which to test the conservation of membrane hypothesis.

\section{Indirect Effects of Deafferentation on Contralateral}

AN-2 Dendrites and Auditory Axons

Given that past work has shown no change in the strength or latency of physiological responses of the AN-2 contralateral to deafferentation [Brodfuehrer and Hoy, 1988], we were surprised to find significant differences in the overall length of the arbor of the contralat- eral AN-2. The length of the lateral dendrites extended significantly farther from the midline than in controls. Though Brodfuehrer and Hoy [1988] showed that AN-2 on the intact side is not physiologically affected by adult deafferentation, an equivalent experiment testing the function of the intact AN-2 after chronic deafferentation throughout larval development has not been done. It will also be important to determine whether this increase in length is unique to chronic deafferentation during larval development, or whether it also occurs after adult deafferentation. Though the response to deafferentation in the juvenile is more robust than that in the adult, it has been assumed to be a continuation of the same process [Brodfuehrer and Hoy, 1988]. A quantification of the deafferentation-induced morphological changes after adult deafferentation could test this assumption.

In response to unilateral deafferentation, contralateral axons apparently form compensatory synapses with deafferented dendrites. We examined the morphology of the intact auditory afferents for changes that might be consistent with this compensatory response. It is important to note that the increase in postsynaptic demand is likely substantial, given that every type of auditory interneuron examined has been shown to grow across the midline after deafferentation and form compensatory synapses with the contralateral afferents [Schildberger et al., 1986]. Yet, this increase in the amount of postsynaptic demand is not thought to compromise the function of existing, ipsilateral synaptic contacts, at least as assessed postsynaptically in AN-2 [Brodfuehrer and Hoy, 1988]. Past work has shown that deafferentation of adult prothoracic ganglia leads to an increased number of afferents crossing the midline from the intact side [Schmitz, 1989]. Our results are the first to demonstrate a significant increase in axonal extension length and volume across the midline in chronically deafferented animals.

It is interesting to speculate on where the compensatory synapses are forming on the deafferented AN-2 dendrites, particularly if these new synapses do not compete with the existing synapses on the AN-2 of the intact side. Our data indicated that there appeared to be two areas for potentially novel synaptic interactions, a region just outside the auditory neuropil and the region just across the midline from the main, intact auditory neuropil. We have observed close apposition of axons and dendrites in both these regions, and suggest that it may make strategic sense for at least some of the new synapses to form in these regions as opposed to the main auditory neuropil as this would be less disruptive to the original synapses. 
Implications for Molecular Control of Compensatory Sprouting

The long-term goal of our research is to identify the molecular cues responsible for the compensatory dendritic sprouting and synaptogenesis that occurs in the cricket after deafferentation. Thus, looking carefully at the particulars of the cellular changes seen after deafferentation can lead to predictions as to the location or type of guidance or growth factors regulated by deafferentation. We were surprised, however, to find that deafferentation appeared to cause sprouting in all three components of the auditory system we examined, albeit in different parts of the neuron (axons vs. dendrites) different locations (midline vs. lateral) and directions (towards deafferentation vs. away from deafferentation). While the compensatory growth of the AN-2 ipsilateral to the injury was likely a direct result of being deafferented, the contralateral AN-2 and auditory afferents were likely influenced indirectly or secondarily by deafferentation.

Deafferentation in a number of organisms has been shown to regulate the transcriptional level of individual or even dozens of different genes [Kwak and Matus, 1988; Mostafapour et al., 2002; Harris et al., 2005; Wang et al., 2005; Schäfer et al., 2008; Wang and Rubel, 2008; Horch et al., 2009]. Discussion of the candidates that may influence this process in crickets is, out of necessity, still speculative since the genome of $G$. bimaculatus has not yet been sequenced. However, we have recently described a large number of candidates downregulated in the cricket after 3 days of deafferentation [Horch et al., 2009], and are continuing to explore the role of commonly conserved proteins in the cricket.

As a first step in this direction, we have included preliminary evidence that the expression of sema2a and vamp are altered in the prothoracic ganglia after deafferentation (fig. 9). The two candidates we chose to explore here are both known to influence dendritic growth during development and, in fact, appear to be differently regulated in the prothoracic ganglion upon deafferentation.

The semaphorins are a family of guidance molecules that influence the growth of developing axons in a variety of species [Tessier-Lavigne and Goodman, 1996]. Semaphorins have also been shown to play important roles in the growth and branching of developing dendrites [Polleux et al., 2000; Fenstermaker et al., 2003; Jan and Jan, 2003; Kim and Chiba, 2004; Morita et al., 2006; Yamashita et al., 2007; Gontheir et al., 2009; Nakamura et al., 2009; Tran et al., 2009]. It has also become clear that semaphorin expression appears to be upregulated after injury in mammals [de Winter et al., 2002; Harel and Strittmatter, 2006; Pasterkamp and Verhaagen, 2006; Pasterkamp and Giger, 2009]. Thus, the upregulation of sema $2 a$ in the prothoracic ganglion after deafferentation suggests it could influence the observed growth of AN-2 dendrites and axons in the cricket.

Conversely, we have found vamp to be downregulated after deafferentation (fig. 9). In addition to the role VAMPs play in synaptic transmission, VAMPs are involved in growth-related exocytosis [Shirasu et al., 2000; Kimura, 2003], and different vamps appear to be differentially regulated after axotomy [Jacobsson et al., 1998], implying a complex regulation of this protein after injury. While it is not clear what role VAMP downregulation is playing in the anatomical plasticity of $\mathrm{AN}-2$ or other auditory neurons, it may be that this downregulation contributes to the observed decrease in the extent and complexity of the lateral AN-2 dendrites. Future experiments exploring the localization of decreased vamp expression will clarify this picture.

Considering the complexity of the responses in a variety of different nervous systems to injury and deafferentation, it is useful to investigate the robust changes observed in a relatively simple system such as the cricket auditory system. Given the conservation of a number of guidance molecules across a broad array of species [Tessier-Lavigne and Goodman, 1996], it is our hope that the general principles of dendritic and axonal growth and plasticity discovered in the cricket will be applicable to other neuronal systems.

\section{Acknowledgments}

This publication was made possible by NIH grant No. P20 RR-016463 from the IDeA Networks of Biomedical Research Excellence Program of the National Center for Research Resources, by NIH grant No. 1 R15 DC006889-01 from the National Institute on Deafness and Other Communication Disorders, and by an Alfred P. Sloan Research Fellowship. We thank R. Thompson and J. Morgan for helpful comments on the manuscript. We also thank Nancy Curtis and Bowdoin's 2007 Molecular Neuroscience class for their contribution to the sequencing of sema $2 a$. 


\section{References}

Baldi A, Calia E, Ciampini A, Riccio M, Vetuschi A, Persico A, Keller F (2000): Deafferentation-induced apoptosis of neurons in thalamic somatosensory nuclei of the newborn rat: critical period and rescue from cell death by peripherally applied neurotrophins. Eur J Neurosci 12:2281-2290.

- Benes FM, Parks TN, Rubel EW (1977): Rapid dendritic atrophy following deafferentation: an electron microscopy morphometric analysis. Brain Res 122:1-13.

Born D, Rubel E (1985): Afferent influences on brain stem auditory nuclei of the chicken: neuron number and size following cochlea removal. J Comp Neurol 231:435-445.

Brodfuehrer PD, Hoy RR (1988): Effect of auditory deafferentation on the synaptic connectivity of a pair of identified interneurons in adult field crickets. J Neurobiol 19:17-38

-Cheng H, Nakamoto M, Bergemann A, Flanagan J (1995): Complementary gradients in expression and binding of ELF-1 and Mek4 in development of the topographic retinotectal projection map. Cell 82:371-381.

-Dalva M, Takasu M, Lin M, Shamah S, Hu L, Gale N, Greenberg M (2000): EphB receptors interact with NMDA receptors and regulate excitatory synapse formation. Cell 103:945-956.

Deitch J, Rubel E (1984): Afferent influences on brain stem auditory nuclei of the chicken: time course and specificity of dendritic atrophy following deafferentation. J Comp Neurol 10:66-79.

Devor M (1975): Neuroplasticity in the rearrangement of olfactory tract fibers after neonatal transection in hamster. J Comp Neurol 166:49-72.

-de Winter F, Oudega M, Lankhorst A, Hamers F, Blits B, Ruitenberg M, Pasterkamp R, Gispen W, Verhaagen J (2002): Injury-induced class 3 semaphorin expression in the rat spinal cord. Exp Neurol 175:61-75.

- Fenstermaker V, Chen Y, Ghosh A, Yuste R (2003): Regulation of dendritic length and branching by semaphorin $3 \mathrm{~A}$. J Neurobiol 58:403-412.

-Furrer M-P, Kim S, Wolf B, Chiba A (2003): Robo and Frazzled/DCC mediate dendritic guidance at the CNS midline. Nature Neurosci 6: 223-230.

Gontheir B, Koncina E, Satkauskas S, Perraut M, Roussel G, Aunis D, Kapfhammer J, Bagnard D (2009): A PKC-dependent recruitment of MMP-2 controls semaphorin-3A growthpromoting effect in cortical dendrites. PLoS One 4:e5099.

-Hall GF, Cohen MJ (1988): The pattern of dendritic sprouting and retraction induced by axotomy of lamprey central neurons. J Neurosci 8:3584-3597.
Hardt M, Watson AH (1994): Distribution of synapses on two ascending interneurones carrying frequency-specific information in the auditory system of the cricket: evidence for GABAergic inputs. J Comp Neurol 345:481-495.

-Hardt M, Watson AHD (1999): Distribution of input and output synapses on the central branches of bushcricket and cricket auditory afferent neurones: immunocytochemical evidence for GABA and glutamate in different populations of presynaptic boutons. J Comp Neurol 403:281-294.

Harel N, Strittmatter S (2006): Can regenerating axons recapitulate developmental guidance during recovery from spinal cord injury? $\mathrm{Na}$ ture Rev Neurosci 7:603-616.

Harris J, Hardie N, Bermingham-McDonogh B, Rubel E (2005): Gene expression differences over a critical period of afferent-dependent neuron survival in the mouse auditory brainstem. J Comp Neurol 493:460-474.

Hirtz R, Wiese K (1997): Ultrastructure of synaptic contacts between identified neurons of the auditory pathway in Gryllus bimaculatus de Geer. J Comp Neurol 386:347-357.

Horch H, McCarthy S, Johansen S, Harris J (2009): Differential gene expression during compensatory sprouting of dendrites in the auditory system of the cricket Gryllus bimaculatus. Insect Mol Biol 18:483-496.

Hoy RR, Nolen TG, Casaday GC (1985): Dendritic sprouting and compensatory synaptogenesis in an identified interneuron following auditory deprivation in a cricket. Proc Natl Acad Sci USA 82:7772-7776.

Jacobsson G, Piehl F, Meister B (1998): VAMP-1 and VAMP-2 gene expression in rat spinal motoneurones: differential regulation after neuronal injury. Eur J Neurosci 10:301-316.

Jan Y-N, Jan L (2003): The control of dendrite development. Neuron 40:229-242.

Kidd T, Bland KS, Goodman CS (1999): Slit is the midline repellent for the Robo receptor in Drosophila. Cell 96:785-794.

Kim S, Chiba A (2004): Dendritic guidance. Trends Neurosci 27:194-202.

Kimura K (2003): Regulation of growth cone extension by SNARE proteins. J Histochem Cytochem 51:429-433.

Komiyama T, Sweeney L, Schuldiner O, Garcia K, Luo L (2007): Graded expression of semaphorin-1a cell-autonomously directs dendritic targeting of olfactory projection neurons. Cell 128:399-410.

Kwak S, Matus A (1988): Denervation induces long-lasting changes in the distribution of microtubule proteins in hippocampal neurons. J Neurocytol 17:189-195.

McAllister A (2002): Conserved cues for axon and dendrite growth in the developing cortex. Neuron 33:2-4.

Mizrahi A, Libersat F (2002): Afferent input regulates the formation of distal dendritic branches. J Comp Neurol 452:1-10.
Morita A, Yamashita N, Sasaki Y, Uchida Y, Nakajima O, Nakamura F, Yagi T, Taniguchi M, Usui H, Datoh-Semba R, Takei K, Goshima Y (2006): Regulation of dendritic branching and spine maturation by semaphorin3A-Fyn signaling. J Neurosci 26:2971-2980.

- Mostafapour S, Mae del Puerto N, Rubel E (2002): bcl-2 overexpression eliminates deprivation-induced cell death of brainstem auditory neurons. J Neurosci 22:4670-4674.

- Murphey RK, Mendenhall B, Palka J, Edwards JS (1975): Deafferentation slows the growth of specific dendrites of identified giant interneurons. J Comp Neurol 159:407-418.

- Nakamura F, Ugahin K, Yamashita N, Okada T, Uchida Y, Taniguchi M, Ohshima T, Goshima Y (2009): Increased proximal bifurcation of CA1 pyramidal apical dendrites in sema $3 \mathrm{~A}$ mutant mice. J Comp Neurol 516:360-375.

Nolan T, Hands RE, Bustin SA (2006): Quantification of mRNA using real-time RT-PCR. Nat Protoc 1:1559-1582

Parks T (1979): Afferent influences on the development of the brain stem auditory nuclei of the chicken: otocyst ablation. J Comp Neurol 183:665-678.

Pasterkamp R, Giger R (2009): Semaphorin function in neural plasticity and disease. Curr Opin Neurobiol 19:263-274.

- Pasterkamp R, Verhaagen J (2006): Semaphorins in axon regeneration: developmental guidance molecules gone wrong? Philos Trans $\mathrm{R}$ Soc Lond B Biol Sci 361:1499-1511.

Polleux F, Ince-Dunn G, Ghosh A (2007): Transcriptional regulation of vertebrate axon guidance and synapse formation. Nat Rev Neurosci 8:331-340.

Polleux F, Morrow T, Ghosh A (2000): Semaphorin $3 \mathrm{~A}$ is a chemoattractant for cortical apical dendrites. Nature 404:567-573.

Poon V, Klassen M, Shen K (2008): UNC-6/netrin and its receptor UNC-5 locally exclude presynaptic components from dendrites. Nature 455:669-673.

Roederer E, Cohen MJ (1983): Regeneration of an identified central neuron in the cricket. 1 . Control of sprouting from soma, dendrites, and axon. J Neurosci 3:1835-1847.

-Schäfer R, Dehn D, Burbach G, Deller T (2008): Differential regulation of chondroitin sulfate proteoglycan mRNAs in the denervated rat fascia dentata after unilateral entorhinal cortex lesion. Neurosci Lett 439:61-65.

-Schildberger K, Wohlers DW, Schmitz B, Kleindienst HU, Huber F (1986): Morphological and physiological changes in central auditory neurons following unilateral foreleg amputation in larval crickets. J Comp Physiol A 158:291-300.

Schmitz B (1989): Neuroplasticity and phonotaxis in monaural adult female crickets (Gryllus bimaculatus de Geer). J Comp Physiol A 164:343-358. 
Schneider GE (1973): Early lesions of superior colliculus: factors affecting the formation of abnormal retinal projections. Brain Behav Evol 8:73-109.

-Shankland M, Bentley D, Goodman CS (1982): Afferent innervation shapes the dendritic branching pattern of the medial giant interneuron in grasshopper embryos raised in culture. Dev Biol 92:507-520.

Sherrard R, Bower A (1998): Role of afferents in the development and cell survival of the vertebrate nervous system. Clin Exp Pharmacol Physiol 25:487-495.

Shirasu M, Kimura K, Kataoka M, Takahashi M, Okajima S, Kawaguchi S, Hirasawa Y, Ide C, Mizoguchi A (2000): VAMP-2 promotes neurite elongation and SNAP-25A increases neurite sprouting in PC12 cells. Neurosci Res $37: 265-275$
Tessier-Lavigne M, Goodman CS (1996): The molecular biology of axon guidance. Science 274:1123-1133.

Tessier-Lavigne M, Placzek M, Lumsden A, Dodd J, Jessell T (1988): Chemotropic guidance of developing axons in the mammalian central nervous system. Nature 336:775-778.

Tran TS, Rubio ME, Clem RL, Johnson D, Case L, Tessier-Lavigne M, Huganir RL, Ginty DD, Kolodkin AL (2009): Secreted semaphorins control spine distribution and morphogenesis in the postnatal CNS. Nature 462: 1065-1069.

ang WZ, Emes RD, Christoffers K, Verrall J, Blackshaw SE (2005): Hirudo medicinalis: a platform for investigating genes in neural repair. Cel Mol Neurobiol 25:427-440.
Wang Y, Rubel E (2008): Rapid regulation of microtubule-associated protein 2 in dendrites of nucleus laminaris of the chick following deprivation of afferent activity. Neuroscience 154:381-389.

Wen Z, Zheng J (2006): Directional guidance of nerve growth cones. Curr Opin Neurobiol $16: 52-58$

Yamashita N, Morita A, Uchida Y, Nakamura F, Usui H, Ohshima T, Taniguchi M, Honnorat J, Thomasset N, Takei K, Takahashi T, Kolattukudy P, Goshima Y (2007): Regulation of spine development by semaphorin $3 \mathrm{~A}$ through cyclin-dependent kinase 5 phosphorylation of collapsin response mediator protein 1. J Neurosci 27:12546-12554. 